\title{
Google Health Trends performance reflecting dengue incidence for the Brazilian states
}

Daniel Romero-Alvarez ${ }^{1,2^{*}}$, Nidhi Parikh², Dave Osthus ${ }^{3}$, Kaitlyn Martinez ${ }^{2,4}$, Nicholas Generous ${ }^{5}$, Sara del Valle ${ }^{2}$ and Carrie A. Manore ${ }^{2}$

\begin{abstract}
Background: Dengue fever is a mosquito-borne infection transmitted by Aedes aegypti and mainly found in tropical and subtropical regions worldwide. Since its re-introduction in 1986, Brazil has become a hotspot for dengue and has experienced yearly epidemics. As a notifiable infectious disease, Brazil uses a passive epidemiological surveillance system to collect and report cases; however, dengue burden is underestimated. Thus, Internet data streams may complement surveillance activities by providing real-time information in the face of reporting lags.

Methods: We analyzed 19 terms related to dengue using Google Health Trends (GHT), a free-Internet data-source, and compared it with weekly dengue incidence between 2011 to 2016. We correlated GHT data with dengue incidence at the national and state-level for Brazil while using the adjusted R squared statistic as primary outcome measure (0/1). We used survey data on Internet access and variables from the official census of 2010 to identify where GHT could be useful in tracking dengue dynamics. Finally, we used a standardized volatility index on dengue incidence and developed models with different variables with the same objective.

Results: From the 19 terms explored with GHT, only seven were able to consistently track dengue. From the 27 states, only 12 reported an adjusted R squared higher than 0.8; these states were distributed mainly in the Northeast, Southeast, and South of Brazil. The usefulness of GHT was explained by the logarithm of the number of Internet users in the last 3 months, the total population per state, and the standardized volatility index.

Conclusions: The potential contribution of GHT in complementing traditional established surveillance strategies should be analyzed in the context of geographical resolutions smaller than countries. For Brazil, GHT implementation should be analyzed in a case-by-case basis. State variables including total population, Internet usage in the last 3 months, and the standardized volatility index could serve as indicators determining when GHT could complement dengue state level surveillance in other countries.
\end{abstract}

Keywords: Google health trends, Digital epidemiology, Brazil, Volatility, Epidemiology, Internet data streams, Internet penetration

\footnotetext{
*Correspondence: daromero88@gmail.com; da.romero@ku.edu; dan_rom@lanl.gov

${ }^{1}$ Department of Ecology \& Evolutionary Biology and Biodiversity Institute, University of Kansas, Lawrence, Kansas, USA

${ }^{2}$ Information Systems and Modeling (A-1), Los Alamos National Laboratory, Los Alamos, NM, USA

Full list of author information is available at the end of the article
}

(c) The Author(s). 2020 Open Access This article is licensed under a Creative Commons Attribution 4.0 International License, which permits use, sharing, adaptation, distribution and reproduction in any medium or format, as long as you give appropriate credit to the original author(s) and the source, provide a link to the Creative Commons licence, and indicate if changes were made. The images or other third party material in this article are included in the article's Creative Commons licence, unless indicated otherwise in a credit line to the material. If material is not included in the article's Creative Commons licence and your intended use is not permitted by statutory regulation or exceeds the permitted use, you will need to obtain permission directly from the copyright holder. To view a copy of this licence, visit http://creativecommons.org/licenses/by/4.0/. The Creative Commons Public Domain Dedication waiver (http://creativecommons.org/publicdomain/zero/1.0/) applies to the data made available in this article, unless otherwise stated in a credit line to the data. 


\section{Background}

Dengue fever is transmitted by the homonymous arthropod-borne virus (i.e., arbovirus) from the family Flaviviridae [1]. There are four dengue virus (DENV) serotypes with a potential fifth serotype described [2], all of them distributed in tropical and subtropical regions worldwide $[3,4]$ with emerging cases in northern latitudes $[5,6]$. The pathogen is mainly transmitted by Aedes aegypti and Ae. albopictus mosquitoes $[1,7,8]$. Dengue disease symptoms range from asymptomatic, mild fever, rash, and joint pain (i.e., dengue with and without warning signs), to life threatening syndromes involving hemorrhagic fever and shock (i.e., severe dengue) [1]; severe clinical presentations are related with immunological cross-reactivity between dengue serotypes $[9,10]$. As a viral infection, treatment is based mainly on support measures during the acute and critical phase of the infection $[1,11]$. Although there has been progress on the development of vaccines, more research is needed before they are used as an effective public health mechanism for control $[1,12,13]$.

The burden of dengue fever is high; around half of the world population is estimated to be at risk of infection [14] and every year, $\sim 100$ million symptomatic cases are detected $[14,15]$. This poses a significant burden to the health systems in at least 128 countries worldwide [15] as well as economic impacts [16] that likely will expand to new regions in the future [3, 8, 17]. In Brazil, dengue was re-introduced in 1986 in the state of Roraima [18, 19] and quickly spread to the rest of the country [13]. In 2018, the total number of cases reported in Brazil was 265,934 [20] and so far 1,439, 471 cases have been reported in 2019 through August [21].

As a notifiable infectious disease, any case of dengue detected in the Brazilian public health system must be reported to the corresponding health authorities [22]. Case notification relies on a passive surveillance framework in which disease reporting builds on patients seeking medical attention [23]. However, cases are often missed by the official reporting system because of non-severe presentations, lack of accessibility to health care infrastructure, misdiagnosis, or even misreporting. Thus, reported case counts are assumed to be an underestimation of the true disease burden [22]. Moreover, availability of health data based on traditional public health surveillance is usually constrained by time, bureaucracy, and staffing, with a lag of 2 weeks for the best systems [24], partial notifications in high burden settings [25], or even complete lack of reporting due to political instability as recently evidenced [26]. Timely disease reporting is critical for preparedness and executable realtime interventions to curb outbreaks [27].

As a consequence, the exploitation of Internet data as a source to characterize epidemiological patterns for communicable and non-communicable diseases has been promoted since the mid-90's under the concept of digital epidemiology [28-31]. These efforts have focused on leveraging freely available information from Twitter, Google, Wikipedia, among others, to follow traces of disease patterns in the population [32-34]. Following the pioneering work of Eysenbach G. on using web-based search queries to track influenza [35] and other efforts that used Google-derived data for influenza in the United States [36, 37] and dengue in different countries [38, 39], Google developed Google Flu Trends (GFT) in 2009 and Google Dengue Trends (GDT) in 2011, as specific disease surveillance tools for digital epidemiology. However, a close examination of the predicting power of these algorithms, specifically GFT, showed signs of over and under prediction and low performance [40-43] cautioning against the broader implementation and applicability of these tools. As a consequence, both GFT and GDT were shut down in 2015 [44]. Nevertheless, two portals remained open to harvest search queries from Google, Google Trends (GT, https://trends.google.com/trends/?geo=US), and Google Health Trends (GHT). GT was released in 2006 as a free and publicly available source, whereas GHT, although free, it requires access through an application private interface (API, https://www.google.org/flutrends/about/). Many researchers have continued using Google-derived data to assess epidemiological patterns and inform epidemiological models for different pathogens with encouraging or conflicting results [45-51].

For Brazil, digital tools to quantify dengue reporting have been previously explored, in fact Chan et al. (2011) inspired the creation of GDT in the first place, showing a strong correlation with dengue cases in Brazil, among other countries [38]. Recently, Marques-Toledo et al. (2017) found that Twitter was useful in characterizing dengue incidence for different Brazilian cities [52], and the authors further compared their results against GT and Wikipedia query logs at the country level finding close agreement among several models [52]. Moreover, Yang et al. (2017) recently used an autoregressive model with Google search queries as exogenous variables (ARGO) to predict dengue cases in Brazil and showed good model performance at the country level [53]. Neither of these studies examined the ability of Google-derived data to characterize dengue incidence at the state level, and in fact, only few studies have examined Google-based algorithms at smaller political administrative levels $[39,50,54]$. To address this gap, we explore the ability of GHT to characterize weekly dengue cases from 2011 to 2016 in Brazil. For this goal, we used 19 dengue-related search terms for all 27 Brazilian states and quantified how Internet penetration data, demographic variables, and a standardized volatility index could determine a-priori where GHT might be a reliable tool.

\section{Methods}

Dengue incidence data

We obtained weekly dengue case counts for Brazil and all its 27 states from January 1st, 2011 to July 31st 2016. 
Data was given by the Brazilian Ministry of Health as a weekly aggregated data sheet with cases identified as counts without any identity information (e.g., names, gender, age, etc) [55]. This data encompasses the number of confirmed and suspected dengue cases reported by the official surveillance system, which follows specific guidelines of mandatory disease notification [22]. Incidence rates were calculated as the number of cases per week divided by the total population per state according to the official Brazilian population census of 2010 [56, 57]; for our analysis we used incidence instead of case counts to allow comparisons of dengue burden between Brazilian states [57].

\section{Google health trends data}

The private API of GHT provides Internet search query data starting in 2004. Queries are sampled from the overall Google dataset in the form of a relative proportion, dividing the number of searches for a specified term over a particular time interval (i.e., days, weeks, months, or years) by the total number of term searches in that time, and multiplied by a predefined constant [58]. Thus, it differs from GT which provides a ranked score from 0 to 100 based on the highest frequency of searches in a particular period of time [58]. We obtained weekly GHT data for the same timeframe of dengue cases using 19 disease and mosquito vector related terms in Portuguese and English, including: "aedes", "Aedes aegypti", "aedes egípcio", "aegypti", dengue", "dengue é vírus", "dengue fever", "dengue hemorrhagic fever", "dengue sintomas", "dengue vírus", "DENV", "DHF" (i.e., dengue hemorrhagic fever), "egípcio", "mosquito", "mosquito dengue", "mosquitoes", "novo vírus da dengue", "sintomas da dengue", and "vírus da dengue". We downloaded the data on June 26th, 2017 and gathered information for the 27 Brazilian states and for the whole country.

\section{Statistical analysis}

We fitted a linear regression model using GHT search terms as predictors of dengue incidence at the state level and recorded the adjusted $\mathrm{R}$ squared statistic as the primary outcome measure $(0 / 1)$. Then, we fitted a multiple linear regression model using all the terms retrieving information by state (i.e., all terms model). Due to the potential overlap from conceptually related terms (e.g., "aedes" and "Aedes aegypti"), we also calculated Pearson's correlation among terms and developed multiple linear regression models with those with a correlation less than 0.7 (i.e., uncorrelated terms model). Finally, we fitted models using four terms: "dengue", "dengue sintomas", "aedes", and "mosquito", which although correlated, have the potential to capture the full spectrum of searches considering the information they provide related to the disease and the mosquito vector (i.e., four terms model). We addressed the statistical differences between models with full vs. reduced number of terms, and between full and individual terms per state using pair-wise analysis of variance (ANOVA).

Given the heterogeneous Internet access throughout Brazil, we analyzed the role that accessibility could play in explaining our ability to track dengue incidence via GHT. Since 2005, Brazil has monitored the accessibility of their population to information and communication technologies $[59,60]$ through the "Survey for Internet Access, Television and Mobile Phone Possession for Personal Use (Acesso à Internet e a Televisão e Posse de Telefone Móvel Celular para Uso Pessoal, Portuguese)" [61]. The survey is part of the National Household Sample Survey (Pesquisa Nacional por Amostra de Domicílios (PNAD), Portuguese) conducted by the Brazilian Institute for Geography and Statistics (Instituto Brasileiro de Geografia e Estatística (IBGE), Portuguese [61]). We analyzed data from the 2015 survey, which included a sample of 356,904 individuals and 151,189 households distributed across the country and was subsequently extrapolated to a total of 177,657 million people and 68 , 037 million households [61, 62]. From all the available variables provided in this survey $(\sim 150)$, we used: (1) the total number of people above 10 years using Internet in the last 3 months, (2) the number of households that have used Internet in the last 3 months, (3) the number of people with mobile phones, and (4) the number of households with computers, as working predictors. In addition to these four variables, we used their logarithmic transformation considering their positive (i.e., right) skewed distribution, for a total of eight variables.

We explored all the available demographic variables from the 2010 official census provided by the IBGE [56]. The census includes information at the municipality level for multiple socio-economic factors including education, sanitation, income, etc., with a total of 237 potential predictors. We aggregated the information to the state level and examined them together with their logarithmic transformations as explained above for a total of 474 variables. Because they represent information with different magnitudes in the form of total counts, percentages, and rates, we normalized all the variables before the analysis. We examined each variable individually with a pair-wise univariate linear regression using the R squared for GHT against dengue cases as a dependent variable; we selected those variables with an adjusted $\mathrm{R}$ squared higher than 0.6 , and performed a Pearson's correlation among those selected to keep those with a score below 0.8 . We then performed a multiple linear regression using the same dependent variable. We compared the ability of the selected variables to quantify GHT usefulness in Brazil using a principal component analysis (PCA) with the 474 predictors and selecting those components recovering more than $90 \%$ of the variance. The Pearson's correlation statistic was also 
implemented in order to assess the relatedness between Internet and demographic variables.

Finally, to determine if variability in the signal of dengue incidence influences GHT accuracy, we computed a standardized volatility index for the dengue incidence data in each state. First, we normalized the dengue incidence time series, subtracting the mean and dividing it by its standard deviation. For this normalized time series, we averaged the absolute difference between each point in the data for each state-incidence per week in this case-to obtain a value representing the stability of dengue incidence (i.e., stable vs. unstable). All analyses were performed in $\mathrm{R}$ programming language [63] using standard packages for statistical analysis.

\section{Results}

The Brazilian states with the overall highest yearly median number of dengue case counts from 2011 to 2016 are: São Paulo $(829 ; \min =52 ; \max =61,944)$, Goiás $(693 ; \min =29$; $\max =9094)$, Minas Gerais $(687 ; \min =13 ; \max =43,424)$, and Rio de Janeiro (635; $\min =12$; $\max =18,602$ ), followed by Ceará $(526 ; \min =5 ; \max =6754)$, Bahia $(507 ; \min =12$; $\max =6654)$, Espírito Santo (382; $\min =11 ; \max =4279$ ), and Pernambuco $(326 ; \min =19 ; \max =5881$; Fig. 1 and Additional file 1: cases/incidences). States such as Rio Grande do Sul and Santa Catarina had a median of 4 and 3 cases, with a minimum of 0 cases and a maximum of 324 and 561 respectively, during the whole study period (Fig. 1 and Additional file 1). Conversely, when considering the weekly dengue incidence, there were two states with the overall highest yearly median values: Goiás (1.154x10e-4; $\min =4.83 \times 10 \mathrm{e}-6 ; \max =1.515 \times 10 \mathrm{e}-3)$ and Espírito Santo $(1.087 x 10 \mathrm{e}-4 ; \quad \min =3.129 \times 10 \mathrm{e}-6 ; \quad \max =1.217 \times 10 \mathrm{e}-3)$, followed by Rio Grande do Norte $(8.996 \times 10 \mathrm{e}-5$; $\min =0$; $\max =1.893 \times 10 \mathrm{e}-3), \quad$ Tocantins $\quad(8.638 \times 10 \mathrm{e}-5 ; \quad \min =$ $3.614 \times 10 \mathrm{e}-6 ; \quad \max =4.539 \times 10 \mathrm{e}-4)$, Alagoas $(8.236 \times 10 \mathrm{e}-5$; $\min =1.602 \times 10 \mathrm{e}-6 ; \quad \max =4.637 \times 10 \mathrm{e}-4), \quad$ Mato Grosso $(7.034 \times 10 \mathrm{e}-5 ; \min =6.59 \times 10 \mathrm{e}-7 ; \max =7.762 \times 10 \mathrm{e}-4)$, Acré $(6.271 \times 10 \mathrm{e}-5 ; \quad \min =0 ; \quad \max =2.931 \times 10 \mathrm{e}-3)$, and Ceará (6.223x10e-5; $\min =5.915 \times 10 \mathrm{e}-7 ; \max =7.991 \times 10 \mathrm{e}-4$; Fig. 1); Santa Catarina and Rio Grande do Sul remained the states with the lowest median of weekly dengue incidence in the whole study period (4.801x10e-7 and $3.740 \times 10 \mathrm{e}-7$, respectively; Fig. 1 and Additional file 1).

From the 19 GHT terms, seven were useful in recovering information for all the Brazilian states, namely: "aedes", "dengue", "mosquito", “aegypti”, “Aedes aegypti", "sintomas da dengue", and "dengue sintomas". From the remaining 12 terms, five never provided information and therefore were discarded in further analysis (Table 1). Six terms tracked dengue for some but not all the states; for example, the word "mosquitoes" were valuable for Distrito Federal, Minas Gerais, and Paraná, but unimportant for Acré, Mato Grosso, or Santa Catarina. Two terms were informative in only one case: "dengue hemorrhagic fever" for São Paulo, and "DENV" for Brazil (Table 1).

As expected, models developed with all the available terms per state fitted better to the weekly incidence dengue data than models developed with only four terms, uncorrelated terms, or with any of the individual terms when measuring the adjusted $\mathrm{R}$ squared statistic (Fig. 2, Table 2, and Additional file 2: adjusted $\mathrm{R}$ squared for individual terms). Individually, the most informative terms among those conceptually related with the disease included "dengue sintomas", "dengue", and "sintomas da dengue" (Fig. 2). Among the terms related with the vectors, "mosquito dengue" and "mosquito" were the most informative (Fig. 2). Correlated and uncorrelated terms for each state are shown in Additional file 3. We used a pair-wise ANOVA between models developed with all terms vs. models developed with reduced combination of terms (i.e., four terms and uncorrelated terms), and the individual terms for each state. From 328 comparisons-different number of terms were available for different states (Tables 1 and 2) - only in ten comparisons a reduced model was statistically comparable (i.e., not different, $F$ statistic with a $p>0.05)$ to the model with all the terms, namely: the models based on four and uncorrelated terms and the model with the word "dengue" for Amapá, models developed with four terms for Distrito Federal, Maranhão, Pará, Rio Grande do Norte, Santa Catarina, and Sergipe, and models developed with uncorrelated terms for Roraima. Thus, for the subsequent analysis we used the adjusted $R$ squared statistic from the models built using all the available terms in each state.

As demonstrated previously, GHT fit the aggregated country-level dengue incidence well (All terms adjusted $\mathrm{R}$ squared $=0.888$, Table 2 and Additional file 4: all plots for Brazil). For Distrito Federal, GHT data was only available starting November 24th, 2013; thus, for this case we performed all the analysis starting that date (Additional file 5: all plots for the 27 states). When analyzing each state separately, GHT was useful in some states but uninformative in others (Fig. 3). The highest adjusted R squared was for Minas Gerais (0.923) and São Paulo (0.930), while the worst fit was for Amapá (0.096) and Roraima (0.093; Fig. 3 and Table 2). Overall, by using all the terms combined, GHT was able to track weekly dengue incidences for 12 states with an adjusted $\mathrm{R}$ squared higher than 0.8, namely: Amazonas, Ceará, Distrito Federal, Maranhão, Minas Gerais, Paraiba, Pernambuco, Paraná, Rio Grande do Norte, Rio Grande do Sul, Santa Catarina, and São Paulo (Table 2). Considering an adjusted $\mathrm{R}$ squared value of 0.7 , we can include four more states in this list: Espírito Santo, Goiás, Mato Grosso do Sul, and Rio de Janeiro, for a total of 16 states were GHT might be implemented for tracking dengue dynamics (Table 2). 


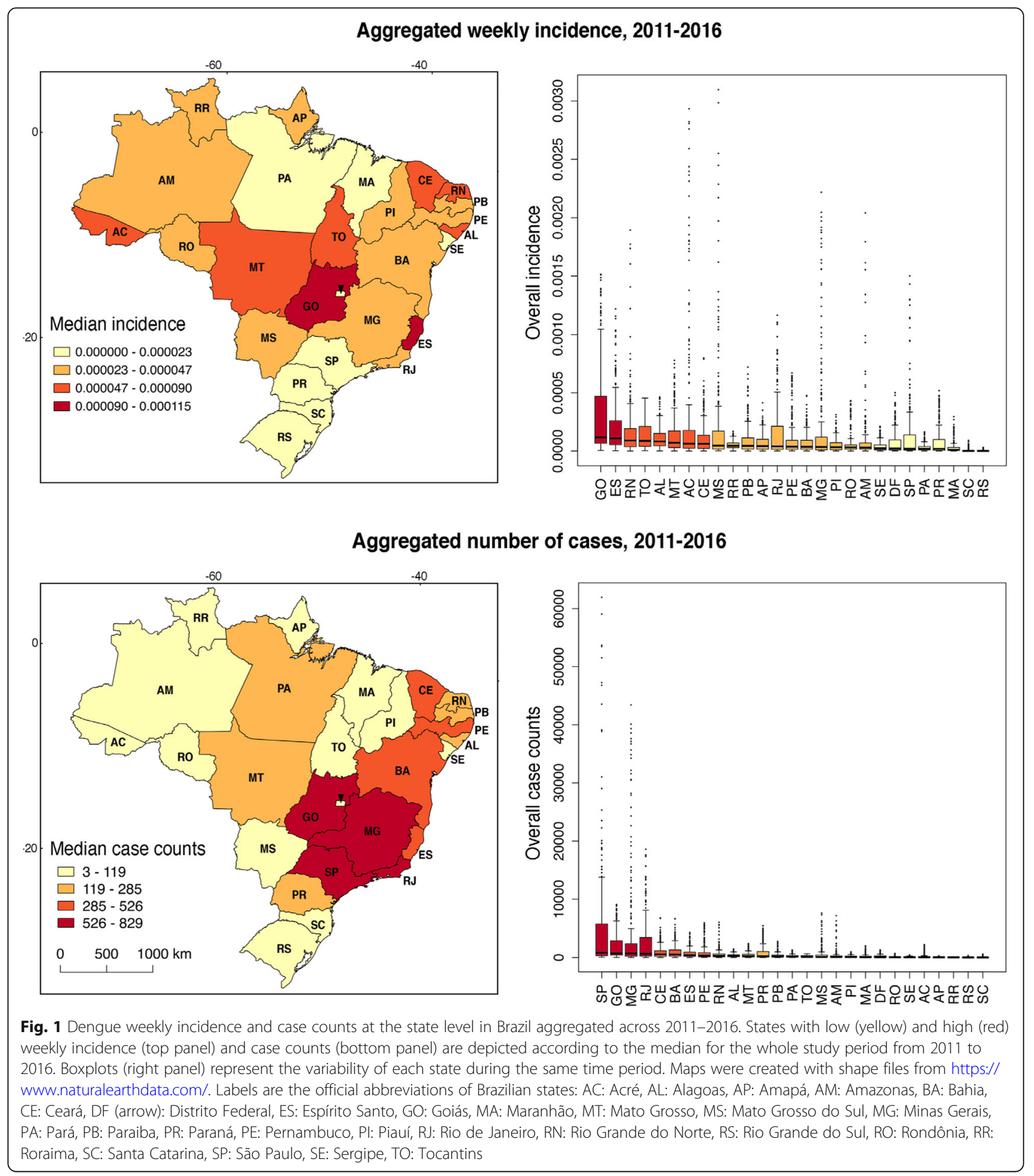

All the Internet data variables were highly correlated with each other (Additional file 6: correlation plot). The logarithm of the number of Internet users per state partially explains when GHT will be able to track dengue incidence (all terms adjusted $\mathrm{R}$ squared $=0.621$, Fig. 4). For instance, in the case of São Paulo and Minas Gerais, with the highest number of Internet users [61], the adjusted R squared for GHT and dengue incidence was high (Fig. 4, log scale); on the other hand, states such as Acré, Amapá, or Roraima with low numbers of Internet users [61] had a lower R squared value (Fig. 4, log scale). States such as Rio Grande do Norte, Amazonas, Paraiba, 
Table 1 Availability of Google Health Trends to track dengue trends in Brazil and its states by term

\begin{tabular}{|c|c|c|c|}
\hline & Terms & $\begin{array}{l}\text { Number of } \\
\text { terms }\end{array}$ & States \\
\hline Informative terms & $\begin{array}{l}\text { "aedes", "dengue", "mosquito", "aegypti", "Aedes aegypti", } \\
\text { "sintomas da dengue", "dengue sintomas" }\end{array}$ & 7 & Brazil and all states \\
\hline Uninformative terms & $\begin{array}{l}\text { "aedes egípcio", "egípcio", "vírus da dengue", "novo } \\
\text { vírus da dengue", "dengue é 'virus" }\end{array}$ & 5 & Brazil and all states \\
\hline \multirow[t]{6}{*}{ Ambiguous terms } & "dengue fever" & 6 & $\begin{array}{l}\text { Brazil and } B A, C E, E S, G O, M G, P B, P R, R J, R S, S P(10 \\
\text { states) }\end{array}$ \\
\hline & "dengue hemorrhagic fever" & & SP (1 state) \\
\hline & "DENV" & & Brazil \\
\hline & "DHF" & & $\begin{array}{l}\text { Brazil and } \mathrm{BA}, \mathrm{GO}, \mathrm{MT}, \mathrm{MG}, \mathrm{PR}, \mathrm{PR}, \mathrm{PE}, \mathrm{RJ}, \mathrm{RS}, \mathrm{SP}(10 \\
\text { states) }\end{array}$ \\
\hline & "dengue vírus" & & $\begin{array}{l}\text { Brazil and AM, BA, CE, DF, ES, GO, MA, MS, MG, PA, PB, } \\
\text { PR, PE, RJ, RN, RS, RO, SC, SP (19 states) }\end{array}$ \\
\hline & "mosquitoes" & & Brazil and DF, MG, PR, RJ, RS, SP (6 states) \\
\hline
\end{tabular}

From the 19 terms explored, only seven were able to consistently track dengue incidence from Google Health Trends in Brazil (i.e., national level) and its individual states. Abbreviations of Brazilian states: AC: Acré, AL: Alagoas, AP: Amapá, AM: Amazonas, BA: Bahia, CE: Ceará, DF: Distrito Federal, ES: Espírito Santo, GO: Goiás, MA: Maranhão, MT: Mato Grosso, MS: Mato Grosso do Sul, MG: Minas Gerais, PA: Pará, PB: Paraiba, PR: Paraná, PE: Pernambuco, PI: Piauí, RJ: Rio de Janeiro, RN: Rio Grande do Norte, RS: Rio Grande do Sul, RO: Rondônia, RR: Roraima, SC: Santa Catarina, SP: São Paulo, SE: Sergipe, TO: Tocantins

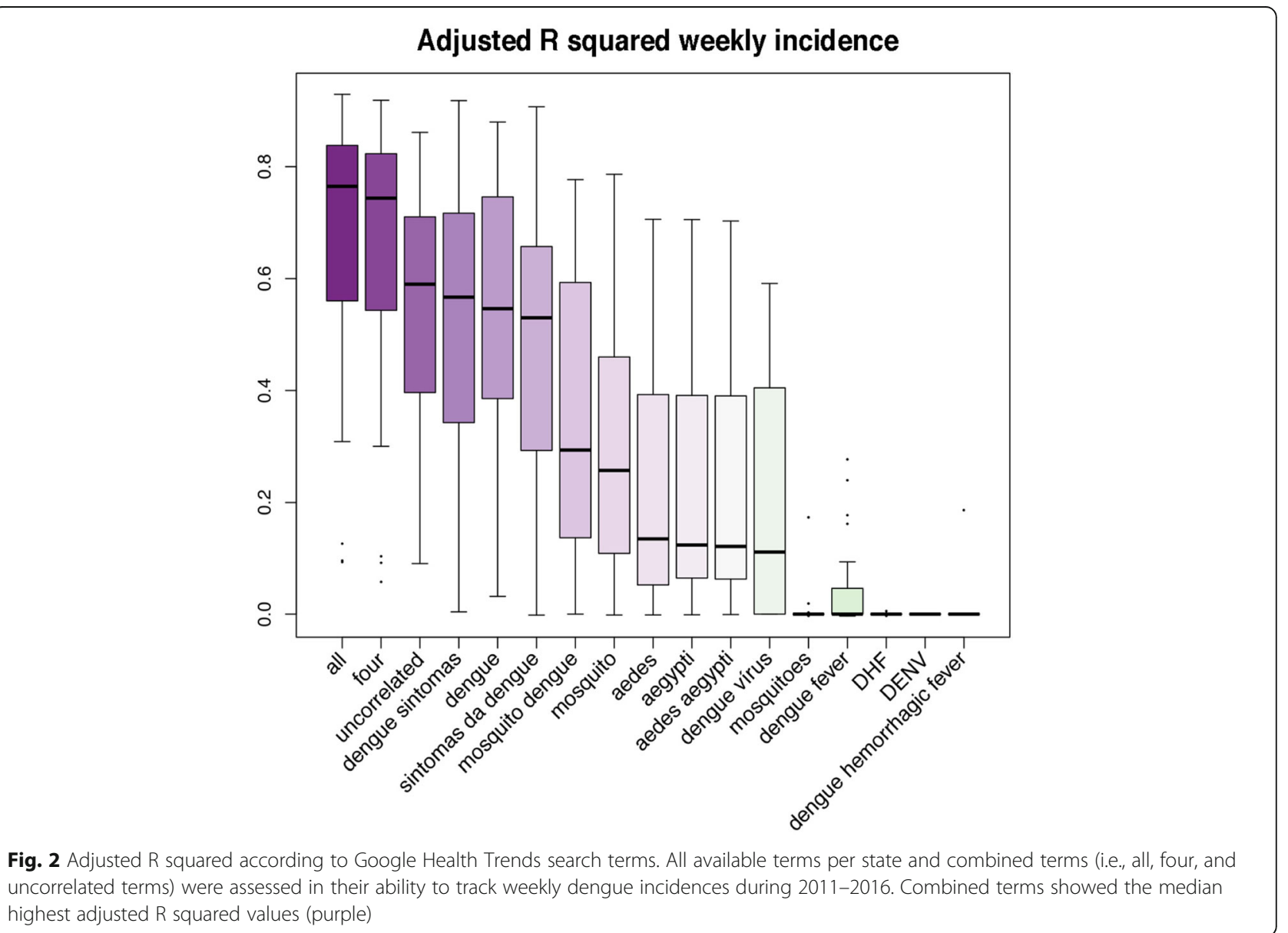


Table 2 Adjusted R squared for multiple linear models using all, uncorrelated, and four available terms

\begin{tabular}{|c|c|c|c|}
\hline State & $\begin{array}{l}\text { Adjusted R squared } \\
\text { - All terms model (n) }\end{array}$ & $\begin{array}{l}\text { Adjusted R squared - } \\
\text { Uncorrelated terms model (n) }\end{array}$ & $\begin{array}{l}\text { Adjusted R squared - } \\
\text { Four terms model }(\boldsymbol{n}=4)\end{array}$ \\
\hline Acré (AC) & $0.126(7)$ & $0.110(6)$ & 0.092 \\
\hline Alagoas (AL) & $0.481(8)$ & $0.418(3)$ & 0.470 \\
\hline Amapá (AP) & $0.096(7)$ & $0.099(6)$ & 0.103 \\
\hline Amazonas (AM) & $0.847(9)$ & $0.590(2)$ & 0.821 \\
\hline Bahia (BA) & $0.647(11)$ & $0.603(3)$ & 0.624 \\
\hline Ceará (CE) & $0.839(10)$ & $0.746(3)$ & 0.812 \\
\hline Distrito Federal (DF) & $0.829(10)$ & $0.433(2)$ & 0.830 \\
\hline Espírito Santo (ES) & $0.725(10)$ & $0.537(3)$ & 0.688 \\
\hline Goiás (GO) & $0.785(11)$ & $0.660(3)$ & 0.768 \\
\hline Maranhão (MA) & $0.859(9)$ & $0.615(2)$ & 0.856 \\
\hline Mato Grosso (MT) & $0.573(9)$ & $0.453(3)$ & 0.559 \\
\hline Mato Grosso do Sul (MS) & $0.713(9)$ & $0.583(3)$ & 0.694 \\
\hline Minas Gerais (MG) & $0.923(12)$ & $0.718(4)$ & 0.919 \\
\hline Pará (PA) & $0.600(9)$ & $0.277(2)$ & 0.596 \\
\hline Paraiba (PB) & $0.837(10)$ & $0.683(3)$ & 0.832 \\
\hline Paraná (PR) & $0.845(12)$ & $0.741(4)$ & 0.821 \\
\hline Pernambuco (PE) & $0.819(10)$ & $0.714(2)$ & 0.808 \\
\hline Piauí (PI) & $0.553(8)$ & $0.377(3)$ & 0.542 \\
\hline Rio de Janeiro (RJ) & $0.765(12)$ & $0.704(5)$ & 0.744 \\
\hline Rio Grande do Norte (RN) & $0.890(9)$ & $0.706(2)$ & 0.891 \\
\hline Rio Grande do Sul (RS) & $0.804(12)$ & $0.724(4)$ & 0.779 \\
\hline Rondônia (RO) & $0.568(9)$ & $0.415(4)$ & 0.544 \\
\hline Roraima (RR) & $0.093(7)$ & $0.091(6)$ & 0.058 \\
\hline Santa Catarina (SC) & $0.826(9)$ & $0.788(2)$ & 0.825 \\
\hline São Paulo (SP) & $0.930(13)$ & $0.861(6)$ & 0.919 \\
\hline Sergipe (SE) & $0.308(8)$ & $0.216(3)$ & 0.300 \\
\hline Tocantins (TO) & $0.415(8)$ & $0.342(4)$ & 0.401 \\
\hline Brazil & $0.888(14)$ & $0.852(7)$ & 0.850 \\
\hline
\end{tabular}

Different numbers of terms (n) were available depending on the state (e.g., São Paulo vs. Acré) and were correlated considering a state-by-state basis (e.g., Amapá vs. Maranhnão; Additional file 3: terms per state). Four terms model was developed with "dengue", "dengue sintomas", "aedes", and "mosquito". Bold represent adjusted $\mathrm{R}$ squared values above 0.8 . Data for Brazil is shown in the last row

and Distrito Federal, had high GHT fit and a low number of Internet users, and viceversa for Rio de Janeiro and Bahia (Fig. 4).

From the 474 census demographic predictors, only 49 had an adjusted $\mathrm{R}$ squared higher than 0.6 , all of which corresponded to variables related to the logarithmic transformation of the state population (see Additional file 7: 49 demographic variables). The 49 variables were highly correlated with each other (minimum $r=0.946$ ); thus, a model including only the logarithm of the total population per state (Fig. 5 top-left panel) was similar to the one using the logarithm of the total number of Internet users (Fig. 4-adjusted $R$ squared $=0.6218$-vs. Fig. 5 top-left panel-adjusted $\mathrm{R}$ squared $=0.6143$ ), a consequence of the high correlation between the predictors involved: population and number of Internet users $(r=0.98)$. Within the PCA framework, the first six PCs recovered 91\% of the variance and a model developed with these components yielded similar results as the ones obtained using either the logarithm of the number of Internet users or the logarithm of total population per state (Adjusted R squared $=0.654$; Additional file 8: PCA results).

States with the highest standardized volatility index, or high variability in reported dengue incidence, had less informative adjusted R squared when fitting GHT to incidence. States with smoother signals of dengue incidence, and therefore low volatility, had a better fit of GHT to incidence, resulting in adjusted R squared values above 0.8 (Fig. 4 and Fig. 5). However, even with a stable dengue incidence signal, GHT was not able to track 


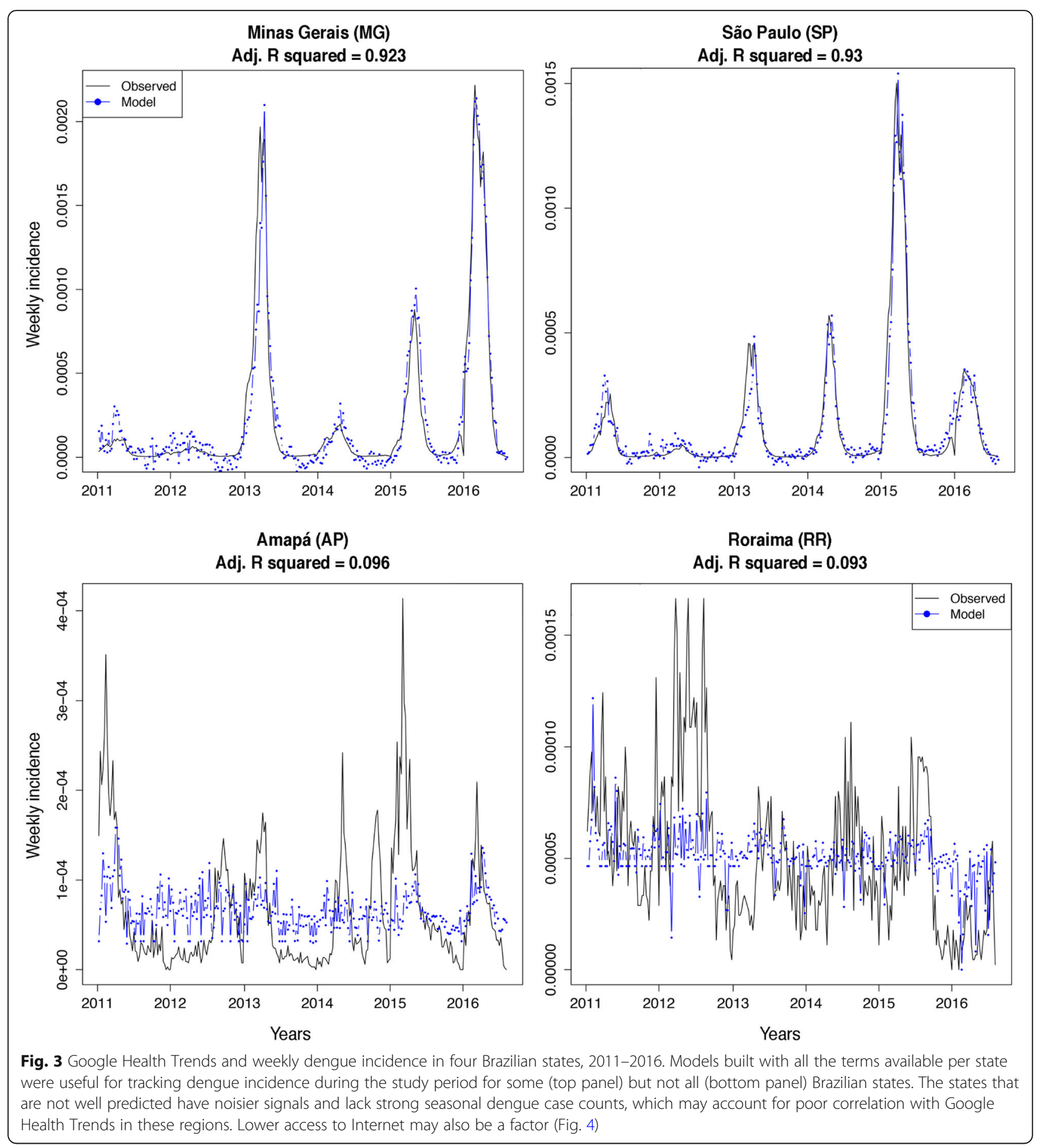

dengue in Acré (Fig. 5 top-right panel). A model using the logarithm of the number of Internet users, the volatility index, and their interaction as predictors of GHT had the highest adjusted $\mathrm{R}$ squared among all the variables explored $(=0.694$, Fig. 5 bottom-right panel). The same model with the logarithm of population instead of Internet users showed a similar adjusted $\mathrm{R}$ squared $(=0.688$, Fig. 5 bottom-left panel). These models were comparable to those using the individual terms of the logarithm of total population, the number of Internet users, or the selected PCs (Figs. 4, 5, and Additional file 8). Eliminating Acré, the state with low volatility but low GHT accuracy (i.e., outlier), we saw an improvement in the models using the standardized volatility index plus its interactions with Internet users or total population (All terms vs. volatility index model, adjusted R squared $=0.717$; all terms vs. Internet users $(\log )+$ 


\section{All terms}

Adj. $\mathbf{R}$ squared $=0.6218$

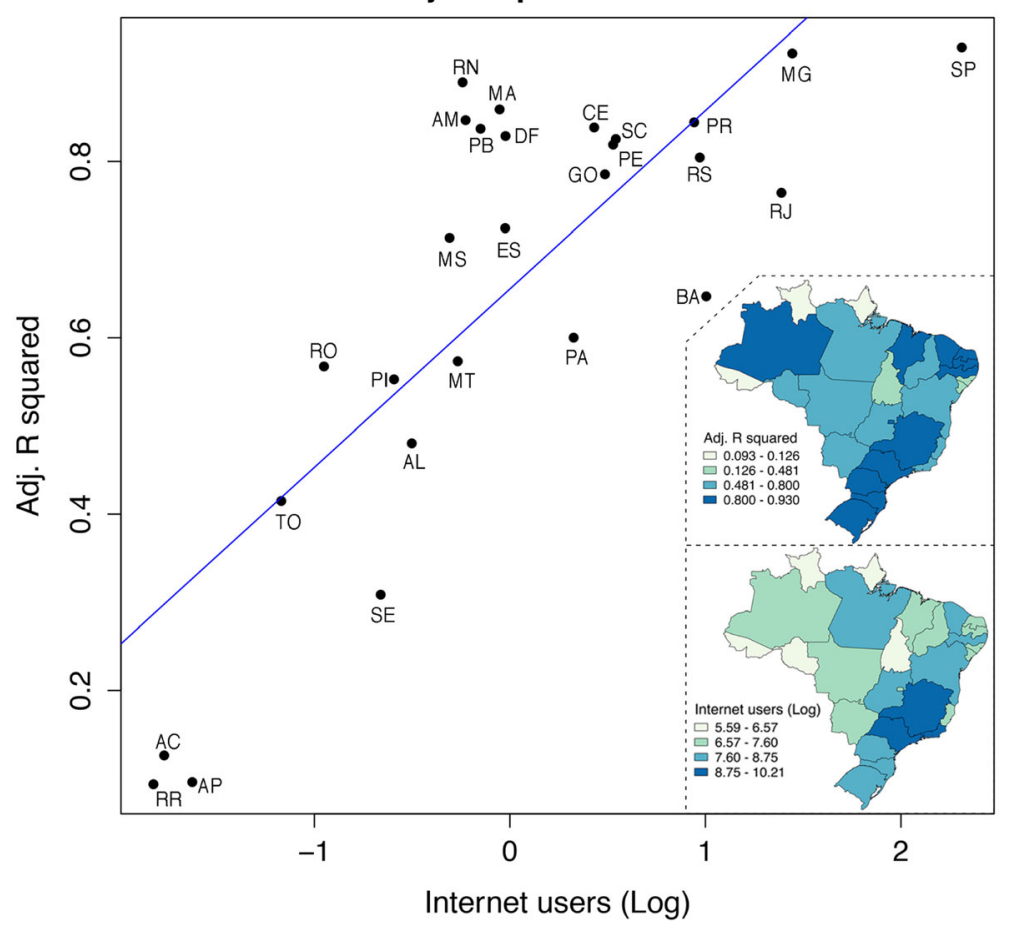

Fig. 4 Logarithm of Internet users and Google Health Trends adjusted R squared. Maps (right panels) depict the adjusted R squared statistic per state when assessing Google Health Trends with their corresponding dengue incidence (linear regression plot). Twelve of 27 states showed values above 0.8 (top, dark blue). The logarithm of Internet users shows that the majority of the Brazilian states with high numbers of Internet users were concentrated at the southeast of Brazil (bottom, dark blue), but the remaining states show limited Internet penetration (pale green). Some states showed low number of Internet users but high GHT data fit (e.g., Amazonas, Maranhão, Paraiba, Distrito Federal). Maps were created with shape files from https://www.naturalearthdata.com/. Abbreviations of Brazilian states: AC: Acré, AL: Alagoas, AP: Amapá, AM: Amazonas, BA: Bahia, CE: Ceará, DF: Distrito Federal, ES: Espírito Santo, GO: Goiás, MA: Maranhão, MT: Mato Grosso, MS: Mato Grosso do Sul, MG: Minas Gerais, PA: Pará, PB: Paraiba, PR: Paraná, PE: Pernambuco, PI: Piauí, RJ: Rio de Janeiro, RN: Rio Grande do Norte, RS: Rio Grande do Sul, RO: Rondônia, RR: Roraima, SC: Santa Catarina, SP: São Paulo, SE: Sergipe, TO: Tocantins

standardized volatility index, adjusted $\mathrm{R}$ squared $=0.793$; and all terms vs. population + standardized volatility index adjusted $\mathrm{R}$ squared $=0.809)$.

\section{Discussion}

Digital surveillance systems have been shown to be useful for predicting country-wide dengue incidence in several countries $[38,53,64]$. Here, we evaluate the usefulness of GHT in tracking dengue incidence both at the country and the state level in Brazil, by evaluating GHT correlation with weekly dengue incidence data over 6 years. We have shown that the performance of GHT varies across states (Fig. 3, Table 2, and additional file 3); however, it is highly correlated with dengue incidence (adjusted $\mathrm{R}$ squared $>0.8$ ) in 12 Brazilian states that are geographically dispersed. Moreover, we showed that proxies of Internet penetration such as the number of Internet users in the last 3 months only partially explain the usefulness of GHT (Fig. 4). In fact, the logarithm of the total population, from among 474 potential demographic predictors, allowed us to build a model that quantified GHT usefulness with similar accuracy to that of Internet penetration data (Fig. 5). The standardized volatility index in combination with the number of Internet users or the total population provided the highest accuracy when predicting GHT usefulness (Fig. 5).

Harvesting epidemiological information from Internetdata streams remains an active area of research for health purposes [31, 46, 49]. Despite its caveats [40], it has the potential to improve and complement traditional disease surveillance methods. In particular, they may be useful in timely outbreak detection and in settings where health surveillance is underdeveloped [31, 65]. However, before implementation, tools such as GHT should be explored at spatial resolutions smaller than countries [39, 50, 54]. Ours is one of the few studies addressing this gap showing that GHT usefulness will be heavily impacted by the political boundaries at which we wish to predict $[52,54]$. In our case, GHT had an adjusted R squared score higher than 0.8 in 12 states, distributed among the five macro-regions of Brazil. The majority of states where GHT successfully 

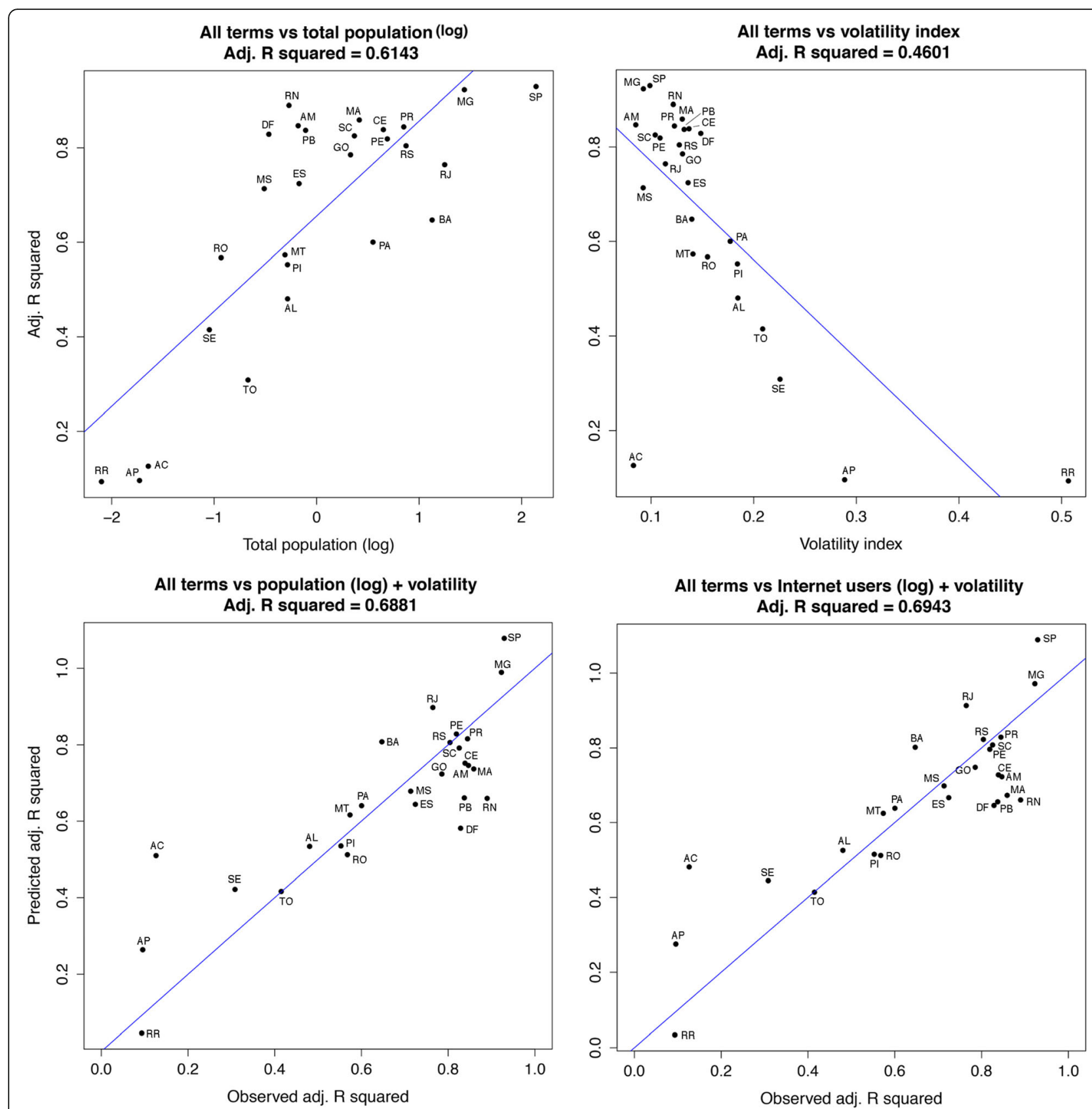

Fig. 5 Total population and volatility index as predictors of Google Health Trends adjusted R squared. From 474 predictors, variables related with population where the most informative anticipating GHT behavior (top-left). The volatility index was useful detecting GHT accuracy although imprecise in some states such as Acré (top-right). Models considering the standardized volatility index and either the total population (bottomleft) or the number of Internet users (bottom-right) were the most informative anticipating GHT accuracy. Abbreviations of Brazilian states: AC: Acré, AL: Alagoas, AP: Amapá, AM: Amazonas, BA: Bahia, CE: Ceará, DF: Distrito Federal, ES: Espírito Santo, GO: Goiás, MA: Maranhão, MT: Mato Grosso, MS: Mato Grosso do Sul, MG: Minas Gerais, PA: Pará, PB: Paraiba, PR: Paraná, PE: Pernambuco, PI: Piauí, RJ: Rio de Janeiro, RN: Rio Grande do Norte, RS: Rio Grande do Sul, RO: Rondônia, RR: Roraima, SC: Santa Catarina, SP: São Paulo, SE: Sergipe, TO: Tocantins

track dengue incidence were located in the SoutheastMinas Gerais and São Paulo-, South-Paraná, Santa Catarina, Rio Grande do Sul-, and Northeast of the country-Ceará, Maranhão, Paraiba, Pernambuco, Rio Grande do Norte-, with the latter concentrating states with higher incidences (Figs. 1 and 4, Table 2). In general, these three macro-regions are considered the most economically developed of Brazil [66]. The Southeast and the South macro-regions have, in general, lower dengue incidence despite having the majority of cases (Fig. 1), highlighting the importance of normalizing measures to allow disease burden comparisons [57]. We calculated incidence rates 
based on the total population of each state to compare dengue burden, showing that high number of dengue cases in the Southeast are explained by the presence of highdensity populations. Among the Southeast, Rio de Janeiro state might benefit from integrating GHT surveillance into dengue modeling and prediction efforts, considering an adjusted R squared of 0.765 (Fig. 1 and Fig. 4, Table 2). At the Northeast, Ceará and Rio Grande do Norte showed higher dengue incidence $(=6.223 \times 10 \mathrm{e}-5$ and $8.996 \times 10 \mathrm{e}-5$, respectively) with a high GHT fit to incidence data (adjusted R squared $=0.839$ and 0.890 , respectively) followed by Paraiba and Pernambuco (adjusted R squared $=0.837$ and 0.819, respectively; Figs. 1 and 4, Table 2).

The remaining states where GHT was able to track dengue incidence were found in the Central-West-Distrito Federal-, and the North-Amazonas-macro-regions, with one state each (Fig. 1 and Fig. 4, Table 2). Both macro-regions represent the fourth and fifth economies of Brazil, respectively [66]. GHT for the Amazonas state could complement traditional clinical surveillance approaches (adjusted $\mathrm{R}$ squared $=0.847$ ) considering its large area extent, moderate dengue incidence aggregated across all years $(=3.014 \times 10 \mathrm{e}-5)$, and geographical location (Western portion of the North macro-region and far from the developed Brazilian Southeast; Fig. 1 and Additional file 1). The North macro-region also included the states of Acré, Amapá, Roraima, and Tocantins where GHT showed a poor behavior due to the low number of Internet users (Table 2 and Fig. 4). Both the North and Central-West areas include states with high dengue incidence consisting of Acré, Goiás, Mato Grosso, and Tocantins (Fig. 1, Additional file 1); among them, only Goiás showed a high GHT fit (adjusted R squared $=0.785$ ); meanwhile the other states showed adjusted $\mathrm{R}$ squared values lower than 0.5 (Table 2 and Fig. 4).

Among the North and Northeast Brazilian macroregions, Maranhão, Pará, and Sergipe have the lower dengue incidence (Fig. 1). For these states, only Maranhão showed a good GHT fit (adjusted R squared $=0.859$ ). The state of Alagoas showed a moderate dengue incidence aggregated across all years $(=8.236 \times 10$ e-5; Fig. 1 and Additional file 1) but poor GHT behavior (adjusted R squared $=0.481$ ) despite being surrounded by states with good GHT performance (e.g., adjusted R squared Pernambuco $=0.819$ and Bahia $=0.647$; Figs. 1 and 4 , Table 2) . We expected Alagoas to have similar dynamics as the rest of its surrounding states due to similar environmental and epidemiological trends, all limited by the Atlantic Ocean with a comparable area extent (Fig. 1). However, variability in local surveillance and mosquito control strategies might account for the differences $[13,22]$.

We suggest that multiple search terms should be explored when using GHT. In our case, only 7 from the initial 19 terms, retrieved information consistently in all the
Brazilian states within our study period (Tables 1 and 2, Additional file 3), from the other terms, information was recovered only in specific instances (e.g., "dengue virus", "dengue fever" for Bahia but not for Acré; Table 1). Models developed with all terms were statistically different from models developed with any of the subset term schemes (i.e., uncorrelated terms, four terms, individual terms) with the exception of ten comparisons. From them, Distrito Federal, Maranhão, Rio Grande do Norte, and Santa Catarina were states in which GHT adjusted R squared was higher than 0.8 (Fig. 4 and Table 2) and the four term model was not statistically different from the full term model $(p>0.05$ in an ANOVA pair-wise comparison). Still, this was not the case for any of the other comparisons (i.e., 318), and more importantly, not for any of the terms individually. We recommend gathering GHT data using multiple terms in order to track dengue incidence dynamics at the state level in Brazil, potentially, this approach would be useful in other countries. While the approach for determining search terms vary, we posit that they should include both keywords (e.g., "dengue") and conceptual words (e.g., "dengue sintomas") [35] and should be selected according to the official and common languages of the country studied, Portuguese and English in our case; for instance, in Singapore searches using English terms were superior than searches using the Malay or Tami local languages [39].

Intuitively, the ability to determine if Internet data is going to be useful should depend on access to information and communication technologies. In this study, we found that the number of Internet users acts as a moderate predictor for GHT performance (Fig. 4). Similarly, Internet penetration has been demonstrated as a dubious variable for data derived from Google search engines [53, 54], and here, we showed that at least for states with both high and low Internet access (e.g., São Paulo, Minas Gerais vs. Acré, Roraima, Fig. 4), this variable can be regarded as a good predictor. However, for states such as Amazonas, Distrito Federal, Paraiba, and Rio Grande do Norte, only relying on the number of Internet users would have been an equivocal signal of GHT usefulness; thus, our data support a case-by-case investigation of Internet data.

Variables related to the total population per state were informative in determining GHT performance (Additional file 7: demographic variables) and these predictors were highly correlated with the total number of Internet users $(r=0.98)$. As Internet penetration increases worldwide [67], the total population per studied political unit, might be a reliable predictor to inform whether or not dengue surveillance based on digital epidemiology tools can complement traditional surveillance. However, other demographic predictors could also serve as indicators of GHT performance. We explored this possibility using various variable selection methods including Pearson's correlation on the full 474 variables, a 
stepwise (i.e., forward and backward) multiple linear regression, and an elastic net regression with L1 normalization (i.e., Least Absolute Shrinkage and Selection Operator or Lasso) using leave-one-out cross validation fashion (Additional file 9: variable selection). Although a combination of five demographic variables allowed us to develop an improved prediction than total population alone (adjusted $\mathrm{R}$ squared $=0.670$ ), how those variables may translate to other countries is not immediately clear (e.g., percentage of population that lives in urban households with garbage collecting services; Additional files 9 and 10: other demographic variables). In addition, models developed using multivariate linear regressions with different variable combinations never outperformed the model developed using PCA (Additional files 8 and 9), or those involving population and the standardized volatility index (Fig. 5, bottom-left panel).

The volatility index discussed here might also aid on addressing when to use GHT predictions for dengue (Fig. 5). In the context of detailed Internet access data, a model considering volatility and Internet users might be a straightforward exploration (Fig. 5). From a practical perspective, due to the potential lack of fine-resolution data on Internet accessibility in other countries, the total number of people plus the described standardized volatility index might be useful indicators of GHT performance. Finally, as has been discussed previously, we also explored if the total number of dengue cases would be a useful predictor to assess GHT performance [31, 54], but this predictor was less useful than any of the others explored (i.e., GHT for all terms vs. logarithm of total number of dengue cases, adjusted R squared $=0.274$ ).

There are some limitations and caveats to our study. For the Distrito Federal state, GHT data was available for half of the study period, thus, we tested the GHT against weekly dengue incidence only for the corresponding timeframe, which involved $\sim 3$ years. The state of Distrito Federal corresponds to a small geographical region established as the capital of the country in 1960 (Fig. 1); we hypothesize that the lack of data was an artifact of Google' algorithm missing the corresponding state before November 2013. Although we do not have any specific evidence of this, it is possibly related to what has been called "blue team dynamics" [40], that is, changes on the search engine can affect how and when GHT gathers data. In the same way, GHT retrieves information as a relative proportion of search volumes, as a consequence GHT data for the Brazilian states will not sum up to the same data at the country level and therefore GHT data for the whole country should be evaluated as an independent unit from its states [58]. This explains issues such as those presented in Table 1 where, for example, the term "DENV" was only available for the whole country and not for any particular state. Regardless, GHT's relative proportion volume represents search patterns in an improved way than the ranked scores from GT. In the majority of studies using the latter, a transformation is needed in order to continue with the analysis [45], this step might add noise to prediction studies with GT.

In the present work, we did not split our data on training-testing datasets, which is a limitation of our approach. However, instead of dealing with prediction ability (i.e., forecasting [39, 49, 53, 54]), we based our evaluation on how GHT reflects dengue incidence in the Brazilian states and where it could inform and complement traditional epidemiological surveillance. Further, we did not include environmental variables known to alter dengue dynamics [54]. To implement GHT as complementary surveillance tool, other sources of uncertainties should be considered, among them, dengue information-seeking behavior might be confounded by the surge of other arbovirus-diseases such as chikungunya or Zika [68], or less well-known pathogens such as Mayaro, Oropouche, or West Nile viruses [69-71], all transmitted by different vectors from the order Diptera, which could trigger local web search behavior. This is especially true because of unspecific initial clinical presentations for those pathogens, media-induced panic or interest [72], and because health campaigns are often aimed towards vector control due to the lack of specific treatments [11]. Moreover, the GHT platform is unstable and could potentially be altered by any update or improvement on Google's search algorithm itself [40] hindering replicability of these kind of studies [65].

Although GHT and other digital tools might be also capturing information from non-infected individuals, searching for the disease terms with different goals or induced by panic related media, it is likely also capturing a portion of the population that is missing medical care for multiple reasons. As has been shown for dengue surveillance in Brazil, the number of patients that are hospitalized and recorded as true "dengue" cases are more than 50\% the number of patients that are actually registered in the official epidemiological surveillance system [22], which is a broad phenomena described also for other countries [73]. Thus, an agreement between suspected dengue cases and GHT would indicate at least the presence of an outbreak.

Despite critics of models based on Google-derived data, several studies are demonstrating the potential usefulness of this approach for epidemiological research and how it can complement other forecasting models [49, 51, 53, 74]. Nonetheless, further studies face another problem: the availability of reliable health data, which is seldom shared in homogeneous user-friendly formats for representative timeframes $[75,76]$. Only by assuring a constant supply of sound, consistent, and truly open access health reports, digital epidemiology could exploit the potential of big data considering the massive, but usually inaccessible, information from the public health domain [76]. 


\section{Conclusions}

Digital epidemiology approaches based on GHT or other tools should be explored beyond country level to consider its actual ability to inform local public health departments. In the case of dengue in Brazil, 12 out of 27 states showed an adjusted $\mathrm{R}$ squared higher than 0.8 , which suggests the potential ability of GHT to complement classical epidemiological surveillance, even though some states had low incidence during the 6-year study period (i.e., 20112016). Models developed with multiple terms were most informative than models using reduced sets or individual terms. Variables such as number of Internet users and total population per state are useful in determining where GHT could complement current surveillance strategies in several Brazilian states. Moreover, both variables benefit from the use of a standardized volatility index for selection of areas of GHT usefulness. The methods proposed here might be applied in other countries to test the ability of GHT to support dengue surveillance. Future studies might also explore the ability of GHT to track dengue using detailed measures of dengue transmission such as the force of infection, only confirmed cases, finer political boundaries (e.g., GHT data is available to particular cities in the world), or different temporal schemes.

\section{Supplementary information}

Supplementary information accompanies this paper at https://doi.org/10. 1186/s12879-020-04957-0.

Additional file 1. Total, median, minimum, and maximum numbers of dengue cases and incidence from the period 2011-2016.

Additional file 2. Adjusted R squared between Google Health Trends and weekly incidence of dengue for Brazil and all the 27 states for individual search terms.

Additional file 3. Available, correlated and uncorrelated terms, and adjusted $\mathrm{R}$ squared for multiple linear models with their corresponding correlation plots.

Additional file 4. Plots of multiple and simple linear models between Google Health Trends data and weekly dengue incidence for Brazil.

Additional file 5. Plots of multiple and simple linear models between Google Health Trends data and weekly dengue incidence for each of the 27 Brazilian states.

Additional file 6. Correlation plot of the Internet access variables selected in the study.

Additional file 7. Definition of 49 demographic variables showing an adjusted $R$ squared higher than 0.6 on a pair-wise linear regression models.

Additional file 8. Results of the principal component analysis of 474 predictors.

Additional file 9. Variables selected by applying different variable selection routines and definitions of each of the selected predictors.

Additional file 10. Description of variables selected according to different methods.

\section{Abbreviations}

API: Application private interface; DHF: Dengue hemorrhagic fever; DENV: Dengue virus; GDT: Google Dengue Trends; GFT: Google Flu Trends;
GHT: Google Health Trends; GT: Google Trends; IBGE: Instituto Brasileiro de Geografia e Estatística (Brazilian Institute for Geography and Statistics, English); PNAD: Pesquisa Nacional por Amostra de Domicílios (National Household Sample Survey, English)

\section{Brazilian states}

AC: Acré; AL: Alagoas; AP: Amapá; AM: Amazonas; BA: Bahia; CE: Ceará; DF: Distrito Federal; ES: Espírito Santo; GO: Goiás; MA: Maranhão; MT: Mato Grosso; MS: Mato Grosso do Sul; MG: Minas Gerais; PA: Pará; PB: Paraiba; PR: Paraná; PE: Pernambuco; PI: Piauí; RJ: Rio de Janeiro; RN: Rio Grande do Norte; RS: Rio Grande do Sul; RO: Rondônia; RR: Roraima; SC: Santa Catarina; SP: São Paulo; SE: Sergipe; TO: Tocantins

\section{Acknowledgements}

We would like to thanks the rest of Los Alamos National Laboratory team working actively on epidemiology including Geoffrey Fairchild, Jessica Conrad, Katherine Kempfert, and Amanda Ziemann.

Further, we extend our thanks to Marcelo Henrique de Araujo, who pointed us to the information and communication technology survey in Brazil.

\section{Authors' contributions}

DRA and CM drafted the first version of the manuscript. DRA, NP, and KM collected data and performed analysis. DO developed statistical indices. DRA, $N P$, and CM designed and coordinated the study. NG, SV, and CM, conceived the study and supervised the project. All authors read, reviewed, and approved the final manuscript.

\section{Funding}

This research was partially funded by the Laboratory Directed Research Development Program at Los Alamos National Laboratory (20190581ECR and 20200033DR), and by NIH/NIGMS under grant R01GM130668. Los Alamos National Laboratory is operated by Triad National Security, LLC under Contract No. 89233218CNA000001 with the U.S. Department of Energy. The content is solely the responsibility of the authors and does not necessarily represent the official views of the sponsors. The funders had no role in study design, data collection and analysis, decision to publish, or preparation of the manuscript.

\section{Availability of data and materials}

Datasets analyzed in the present study are available from the corresponding author on reasonable request.

Ethics approval and consent to participate

The Ministry of Public Health from Brazil handed out weekly case counts. No information associated with personal information of the cases was disclosed or used for the development of this study.

\section{Consent for publication}

Not applicable.

\section{Competing interests}

The authors declare that they have no competing interests.

\section{Author details}

${ }^{1}$ Department of Ecology \& Evolutionary Biology and Biodiversity Institute, University of Kansas, Lawrence, Kansas, USA. ${ }^{2}$ Information Systems and Modeling (A-1), Los Alamos National Laboratory, Los Alamos, NM, USA. ${ }^{3}$ Statistical Sciences (CCS-6), Los Alamos National Laboratory, Los Alamos, NM, USA. ${ }^{4}$ Applied Math and Statistics, Colorado School of Mines, Golden, CO, USA. ${ }^{5}$ National Security \& Defense Program Office (GS-NSD), Los Alamos National Laboratory, Los Alamos, NM, USA.

Received: 11 November 2019 Accepted: 10 March 2020 Published online: 26 March 2020

\section{References}

1. Guzman MG, Gubler DJ, Izquierdo A, Martinez E, Halstead SB. Dengue infection. Nat Rev Dis Prim. 2016:2:16055.

2. Mustafa MS, Rasotgi V, Jain S, Gupta V. Discovery of fifth serotype of dengue virus (DENV-5): a new public health dilemma in dengue control. Med J Armed Forces India. 2015;71:67-70. 
3. Messina JP, Brady OJ, Golding N, Kraemer MU, Wint GW, Ray SE, et al. The current and future global distribution and population at risk of dengue. Nat Microbiol. 2019;4:1508-15.

4. Messina JP, Brady OJ, Pigott DM, Brownstein JS, Hoen AG, Hay SI. A global compendium of human dengue virus occurrence. Sci Data. 2014;1:140004.

5. Tomasello D, Schlagenhauf P. Chikungunya and dengue autochthonous cases in Europe, 2007-2012. Travel Med Infect Dis. 2013;11:274-84.

6. Semenza JC, Suk JE. Vector-borne diseases and climate change: a European perspective. FEMS Microbiol Lett. 2017;365:fn×244.

7. Kraemer MU, Sinka ME, Duda KA, Mylne AQ, Shearer FM, Barker CM, et al. The global distribution of the arbovirus vectors Aedes aegypti and Ae. Albopictus. Elife. 2015;4:e08347.

8. Kamal M, Kenawy MA, Rady MH, Khaled AS, Samy AM. Mapping the global potential distributions of two arboviral vectors Aedes aegypti and Ae. albopictus under changing climate. PLoS One. 2018;13:e0210122.

9. de Alwis R, Williams KL, Schmid MA, Lai CY, Patel B, Smith SA, et al. Dengue viruses are enhanced by distinct populations of serotype cross-reactive antibodies in human immune sera. PLoS Pathog. 2014;10:e1004386.

10. Guzman MG, Alvarez M, Halstead SB. Secondary infection as a risk factor for dengue hemorrhagic fever/dengue shock syndrome: an historical perspective and role of antibody-dependent enhancement of infection. Arch Virol. 2013;158:1445-59.

11. World Health Organization (WHO). Special Programme for Research and Training in Tropical Diseases (TDR). Dengue: guidelines for diagnosis, treatment, prevention, and control. Geneva: WHO; 2009. https://www.who. int/tdr/publications/training-guideline-publications/dengue-diagnosistreatment/en/.

12. Gil L, Lazo L. Effective dengue vaccines: a pipe dream? Viral Immunol. 2019;32:236-8.

13. Salles TS, Sá-Guimarães TDE, Alvarenga ESLD, Guimarães-Ribeiro V, Meneses MDF, Castro-Salles PF, et al. History, epidemiology and diagnostics of dengue in the American and Brazilian contexts: a review. Parasit Vectors. 2018;11:264

14. Bhatt $\mathrm{S}$, Gething PW, Brady OJ, Messina JP, Farlow AW, Moyes $C L$, et al. The global distribution and burden of dengue. Nature. 2013;496:504-7.

15. Stanaway JD, Shepard DS, Undurraga EA, Halasa YA, Coffeng LE, Brady OJ, et al. The global burden of dengue: an analysis from the global burden of disease study 2013. Lancet Infect Dis. 2016;16:712-23.

16. Shepard DS, Coudeville L, Halasa YA, Zambrano B, Dayan GH. Economic impact of dengue illness in the Americas. Am J Trop Med Hyg. 2011;84:200-7.

17. Campbell LP, Luther C, Moo-Llanes D, Ramsey JM, Danis-Lozano R, Peterson AT. Climate change influences on global distributions of dengue and chikungunya virus vectors. Philos Trans R Soc B. 2015;370:20140135.

18. Rodriguez-Barraquer I, Cordeiro MT, Braga C, Souza WW, Marques ET, Cummings DAT. From re-emergence to hyperendemicity: the natural history of the dengue epidemic in Brazil. PLoS Negl Trop Dis. 2011;5:e935.

19. Gubler DJ. Dengue, urbanization and globalization: the unholy trinity of the 21st century. Trop Med Health. 2011;39:S3-S11.

20. Ministério da Saúde, Brasil. Secretaria de Vigilância em Saúde. Boletim Epidemiológico 04. Semana Epidemiológica 52 de 2018, vol. 50; 2019. http://portalarquivos2.saude.gov.br/images/pdf/2019/janeiro/28/2019-002. pdf. Accessed 28 Oct 2019

21. Ministério da Saúde, Brasil. Secretaria de Vigilância em Saúde. Boletim Epidemiológico 22. Semana Epidemiológica 34 de 2019, vol. 50; 2019. https://portalarquivos2.saude.gov.br/images/pdf/2019/setembro/11/BEarbovirose-22.pdf. Accessed 28 Oct 2019.

22. Coelho GE, Leal PL, Cerroni MDP. Sensitivity of the dengue surveillance system in Brazil for detecting hospitalized cases. PLoS Negl Trop Dis. 2016; 10:e0004705.

23. Nsubuga P, White ME, Thacker SB, Anderson MA, Blount SB, Broome CV, et al. Chapter 53: Public health surveillance: a tool for targeting and monitoring interventions. In: Jamison DT, Breman JG, Measham AR, et al., editors. Disease control priorities in developing countries. 2nd ed. Washington, DC: World Bank and Oxford University Press; 2006. p. 997-1015.

24. Moran KR, Fairchild G, Generous N, Hickmann K, Osthus D, Priedhorsky R, et al. Epidemic forecasting is messier than weather forecasting: the role of human behavior and internet data streams in epidemic forecast. J Infect Dis. 2016;214:S404-8

25. Romero-Alvarez D, Peterson AT, Escobar LE. Surveillance fatique (fatigatio vigilantiae) during epidemics. Rev Chil Infectol. 2017;34:289-90.

26. Grillet ME, Hernández-Villena JV, Llewellyn MS, Paniz-Mondolfi AE, Tami A Vincenti-Gonzalez MF, et al. Venezuela's humanitarian crisis, resurgence of vector-borne diseases, and implications for spillover in the region. Lancet Infect Dis. 2019:19:e149-61.

27. Kluberg SA, Mekaru SR, Mclver DJ, Madoff LC, Crawley AW, Smolinski MS, et al. Global capacity for emerging infectious disease detection, 1996-2014. Emerg Infect Dis. 2016;22:10

28. Salathé M. Digital epidemiology: what is it, and where is it going? Life Sci Soc Policy. 2018;14:1-5.

29. Brownstein JS, Freifeld CC, Reis BY, Mandl KD. Surveillance sans Frontières: internet-based emerging infectious disease intelligence and the HealthMap project. PLoS Med. 2008:5:e151.

30. Hugh-Jones M. Global awareness of disease outbreaks: the experience of ProMED-mail. Public Health Rep. 2001;116:S27-31.

31. Pollett S, Althouse BM, Forshey B, Rutherford GW, Jarman RG. Internet-based biosurveillance methods for vector-borne diseases: are they novel public health tools or just novelties? PLoS Negl Trop Dis. 2017:11:e0005871.

32. Jordan SE, Hovet SE, Fung ICH, Liang H, Fu K-W, Tse ZTH. Using twitter for public health surveillance from monitoring and prediction to public response. Data. 2018:4:6.

33. Priedhorsky R, Osthus D, Daughton AR, Moran KR, Generous N, Fairchild G, et al. Measuring global disease with Wikipedia: success, failure, and a research agenda. Proc 2017 ACM Conf Comput Support Coop Work Soc Comput. 2017;1:1812-34.

34. Milinovich GJ, Williams GM, Clements ACA, Hu W. Internet-based surveillance systems for monitoring emerging infectious diseases. Lancet Infect Dis. 2014;14:160-8.

35. Eysenbach $\mathrm{G}$. Infodemiology and infoveillance: framework for an emerging set of public health informatics methods to analyze search, communication and publication behavior on the internet. J Med Internet Res. 2009;11:e11.

36. Ginsberg J, Mohebbi MH, Patel RS, Brammer L, Smolinski MS, Brilliant L. Detecting influenza epidemics using search engine query data. Nature. 2009;457:1012-4.

37. Polgreen PM, Chen Y, Pennock DM, Nelson FD, Weinstein RA. Using internet searches for influenza surveillance. Clin Infect Dis. 2008;47:1443-8.

38. Chan EH, Sahai V, Conrad C, Brownstein JS. Using web search query data to monitor dengue epidemics: a new model for neglected tropical disease surveillance. PLoS Negl Trop Dis. 2011;5:e1206.

39. Althouse BM, Ng YY, Cummings DAT. Prediction of dengue incidence using search query surveillance. PLoS Negl Trop Dis. 2011;5:e1258.

40. Lazer D, Kennedy R, King G, Vespignani A. The parable of Google Flu: traps in big data analysis. Science. 2014;343:1203-5.

41. Cook S, Conrad C, Fowlkes AL, Mohebbi MH. Assessing Google flu trends performance in the United States during the 2009 influenza virus a (H1N1) pandemic. PLoS One. 2011;6:e23610.

42. Ortiz JR, Zhou H, Shay DK, Neuzil KM, Fowlkes AL, Goss CH. Monitoring influenza activity in the United States: a comparison of traditional surveillance systems with Google flu trends. PLoS One. 2011;6:e18687.

43. Pollett S, Boscardin WJ, Azziz-Baumgartner E, Tinoco YO, Soto G, Romero C, et al. Evaluating Google flu trends in Latin America: important lessons for the next phase of digital disease detection. Clin Infect Dis. 2016;64:34-41.

44. Google Al Blog. The next chapter for Flu Trends. https://ai.googleblog.com/2 015/08/the-next-chapter-for-flu-trends.html. Accessed 28 October 2019.

45. Kapitány-Fövény M, Ferenci T, Sulyok Z, Kegele J, Richter $H$, Vályi-Nagy I, et al. Can Google trends data improve forecasting of Lyme disease incidence? Zoonoses Public Health. 2019;66:101-7.

46. Arora VS, Mckee MM, Stuckler D. Google trends: opportunities and limitations in health and health policy research. Health Policy. 2019;123:338-41.

47. Teng $Y$, Bi D, Xie G, Jin Y, Huang $Y$, Lin B, et al. Dynamic forecasting of Zika epidemics using Google trends. PLoS One. 2017;12:e0165085.

48. Cervellin G, Comelli I, Lippi G. Is Google trends a reliable tool for digital epidemiology? Insights from different clinical settings. J Epidemiol Glob Health. 2017;7:185-9.

49. Rohart F, Milinovich GJ, Avril SMR, Cao KL, Tong S. Disease surveillance based on internet-based linear models: an Australian case study of previously unmodeled infection diseases. Sci Rep. 2016;6:38522.

50. Ho HT, Carvajal TM, Bautista JR, Capistrano JDR, Viacrusis KM, Hernandez LFT, et al. Using Google trends to examine the spatio-temporal incidence and behavioral patterns of dengue disease: a case study in metropolitan Manila, Philippines. Trop Med Infect Dis. 2018;3:118.

51. Osthus D, Daughton AR, Priedhorsky R. Even a good influenza forecasting model can benefit from internet-based nowcasts, but those benefits are limited. PLoS Comput Biol. 2019;15:e1006599.

52. Marques-Toledo CDA, Degener CM, Vinhal L, Coelho G, Meira W, Codeço $C T$, et al. Dengue prediction by the web: tweets are a useful tool for 
estimating and forecasting dengue at country and city level. PLoS Negl Trop Dis. 2017;11:e0005729.

53. Yang S, Kou SC, Lu F, Brownstein JS, Brooke N, Santillana M. Advances in using internet searches to track dengue. PLoS Comput Biol. 2017;13:e1005607.

54. Gluskin RT, Johansson MA, Santillana M, Brownstein JS. Evaluation of internet-based dengue query data: Google dengue trends. PLoS Negl Trop Dis. 2014;8:e2713.

55. Ministério da Saúde, Brasil. Informes Arboviroses. http://saude.gov.br/ informes-de-arboviroses. Accessed 28 Oct 2019.

56. Instituto Brasileiro de Geografia e Estatística. Censo Demográfico 2010. https://ww2.ibge.gov.br/home/estatistica/populacao/censo2010/default. shtm. Accessed 28 October 2019.

57. Vandenbroucke JP, Pearce N. Incidence rates in dynamic populations. Int J Epidemiol. 2012;41:1472-9.

58. Stocking G, Matsa KE. Using Google trends data for research? Here are 6 questions to ask. Pew Research Center. https://medium.com/@pewresearch/ using-google-trends-data-for-research-here-are-6-questions-to-ask-a7097f5 fb526. Accessed 28 Oct 2019.

59. Nishijima M, Ivanauskas TM, Sarti FM. Evolution and determinants of digital divide in Brazil (2005-2013). Telecommun Policy. 2017;41:12-24.

60. Araujo MHD, Reinhard N. Categorization of Brazilian internet users and its impacts on the use of electronic government sevices. JISTEM. 2016;13:241-54.

61. Pesquisa Nacional Por Amostra de Domicilios 2015. https://www.lo.org/ surveydata/index.php/catalog/1548. Accessed 26 June 2019.

62. Instituto Brasileiro de Geografia e Estatística. Acesso à Internet e a televisão e posse de telefone móvel celular para uso pessoal. https://sidra.ibge.gov. br/pesquisa/pnad/suplementos/acesso-a-internet-e-a-televisao-e-posse-detelefone-movel-celular-para-uso-pessoal. Accessed 28 Oct 2019.

63. R Core Team. The R Project for Statistical Computing. R Foundation for Statistical Computing. 2018. https:/www.r-project.org/. Accessed 17 Jan 2019

64. Husnayain A, Fuad A, Lazuardi L, Husnayain A. Correlation between Google trends on dengue fever and national surveillance report in Indonesia. Glob Health Action. 2019;12:1552652.

65. Nuti SV, Wayda B, Ranasinghe I, Wang S, Dreyer RP, Chen SI, et al. The use of Google trends in health care research: a systematic review. PLoS One. 2014;9:e109583.

66. Caldana VM, Silva MTD. Regional development and engineering education: an analysis of Brazil's micro-regional scenario. Prod. 2017;27:e20162250.

67. The World Bank. Individuals using the Internet (\% of population) | Data. https://data. worldbank.org/indicator/IT.NET.USER.ZS?end=2017\&start=196 0\&view=chart. Accessed 28 Oct 2019.

68. Paixão ES, Teixeira MG, Rodrigues LC. Zika, chikungunya and dengue: the causes and threats of new and re-emerging arboviral diseases. BMJ Glob Health. 2018;2:e000530.

69. Mackay IM, Arden KE. Mayaro virus: a forest virus primed for a trip to the city? Microbes Infect. 2016;18:724-34.

70. Martins LC, Silva EVPD, Casseb LMN, Silva SPD, Cruz ACR, Pantoja JADS, et al. First isolation of West Nile virus in Brazil. Mem Inst Oswaldo Cruz. 2019;114:e180332.

71. Romero-Alvarez D, Escobar LE. Oropouche fever, an emergent disease from the Americas. Microbes Infect. 2017;20:135-46.

72. Southwell BG, Dolina S, Jimenez-Magdaleno K, Squiers LB, Kelly BJ. Zika virus-related news coverage and online behaviour, United States, Guatemala, and Brazil. Emerg Infect Dis. 2016;22:1320.

73. Wichmann O, Yoon IK, Vong S, Limkittikul K, Gibbons RV, Mammen MP, et al. Dengue in Thailand and Cambodia: an assessment of the degree of underrecognized disease burden based on reported cases. PLoS Negl Trop Dis. 2011;5:e996.

74. McGough SF, Brownstein JS, Hawkins JB, Santillana M. Forecasting Zika incidence in the 2016 Latin America outbreak combining traditional disease surveillance with search, social media, and news report data. PLoS Negl Trop Dis. 2017;11:e0005295.

75. Fairchild G, Tasseff B, Khalsa H, Generous N, Daughton AR, Velappan N, et al. Epidemiological data challenges: planning for a more robust future through data standards. Front Public Health. 2018;6:336.

76. Van Panhuis WG, Paul P, Emerson C, Grefenstette J, Wilder R, Herbst AJ, et al. A systematic review of barriers to data sharing in public health. BMC Public Health. 2014;14:1144.

\section{Publisher's Note}

Springer Nature remains neutral with regard to jurisdictional claims in published maps and institutional affiliations.

Ready to submit your research? Choose BMC and benefit from:

- fast, convenient online submission

- thorough peer review by experienced researchers in your field

- rapid publication on acceptance

- support for research data, including large and complex data types

- gold Open Access which fosters wider collaboration and increased citations

- maximum visibility for your research: over $100 \mathrm{M}$ website views per year

At BMC, research is always in progress.

Learn more biomedcentral.com/submissions 